Multimedia Appendix 1. Assignment of CHARISMHA [1] function type groups vs. subject areas (both assigned manually, one hit per dimension allowed).

Function type groups as defined in CHARISMHA

(manually assigned)

Provision of Support Data acquisiinformation tion, processing and evaluation
Cumulated number of apps per topic (out of $\mathrm{N}=335$ )

\title{
Topic (manually assigned)
}

\begin{tabular}{|c|c|c|c|c|c|c|c|c|}
\hline Health data & 3 & 22 & 28 & 10 & - & 4 & 67 & 20 \\
\hline Other & 31 & 3 & 8 & - & 2 & 1 & 45 & 13.4 \\
\hline Emergencies & 32 & 7 & - & - & 5 & - & 44 & 13.1 \\
\hline Blood pressure & 1 & 4 & 5 & 26 & - & - & 36 & 10.7 \\
\hline $\begin{array}{l}\text { Complementary } \\
\text { medicine }\end{array}$ & 7 & 24 & - & - & - & - & 31 & 9.3 \\
\hline Metabolism & 4 & 2 & 3 & 9 & - & - & 18 & 5.4 \\
\hline ECG & 7 & - & 6 & 1 & 1 & - & 15 & 4.5 \\
\hline Conferences & 14 & - & - & - & - & - & 14 & 4.2 \\
\hline Medication & 5 & 2 & 2 & 3 & - & - & 12 & 3.6 \\
\hline Atlases & 10 & - & - & - & - & - & 10 & 3 \\
\hline Communication & 2 & - & 1 & 1 & 6 & - & 10 & 3 \\
\hline $\begin{array}{l}\text { Medical practice } \\
\text { or hospital }\end{array}$ & 7 & - & 1 & - & 2 & - & 10 & 3 \\
\hline Psyche & - & 4 & 2 & - & - & - & 6 & 1.8 \\
\hline Sleep & 4 & - & 2 & - & - & - & 6 & 1.8 \\
\hline Animals & 1 & 1 & 1 & 1 & - & - & 4 & 1.2 \\
\hline Neurology & 2 & - & 1 & - & - & - & 3 & 0.9 \\
\hline Women & - & 2 & - & - & - & - & 2 & 0.6 \\
\hline Nutrition & - & - & - & 1 & - & - & 1 & 0.3 \\
\hline Fitness & - & 1 & - & - & - & - & 1 & 0.3 \\
\hline \multicolumn{9}{|c|}{ lated number of apps per function type (out of $N=335$ ) } \\
\hline $\begin{array}{l}\text { Cumulated number of } \\
\text { apps }\end{array}$ & 130 & 72 & 60 & 52 & 16 & 5 & 335 & 100 \\
\hline $\begin{array}{l}\text { Percentage of apps per } \\
\text { function type }\end{array}$ & 38.8 & 21.5 & 17.9 & 15.5 & 4.8 & 1.5 & 100 & \\
\hline
\end{tabular}

1. Albrecht U-V, Höhn M, von Jan U. Kapitel 2. Gesundheits-Apps und Markt. In: Albrecht U-V, editor. Chancen und Risiken von Gesundheits-Apps (CHARISMHA), engl Chances and Risks of Mobile Health Apps (CHARISMHA). Hannover: Medizinische Hochschule Hannover; 2016. 62-82 